Numerical simulations of daytime temperature and humidity crossover effects in London

--Manuscript Draft--

\begin{tabular}{|c|c|}
\hline Manuscript Number: & BOUN-D-14-00002R4 \\
\hline Full Title: & $\begin{array}{l}\text { Numerical simulations of daytime temperature and humidity crossover effects in } \\
\text { London }\end{array}$ \\
\hline Article Type: & Research Article \\
\hline Keywords: & Crossover; London; Mesoscale model; Numerical modelling; Urban heat island \\
\hline Corresponding Author: & $\begin{array}{l}\text { Nathan Sparks } \\
\text { Imperial College } \\
\text { UNITED KINGDOM }\end{array}$ \\
\hline \multicolumn{2}{|l|}{$\begin{array}{l}\text { Corresponding Author Secondary } \\
\text { Information: }\end{array}$} \\
\hline Corresponding Author's Institution: & Imperial College \\
\hline \multicolumn{2}{|l|}{$\begin{array}{l}\text { Corresponding Author's Secondary } \\
\text { Institution: }\end{array}$} \\
\hline First Author: & Nathan Sparks \\
\hline \multicolumn{2}{|l|}{ First Author Secondary Information: } \\
\hline \multirow[t]{2}{*}{ Order of Authors: } & Nathan Sparks \\
\hline & Ralf Toumi \\
\hline \multicolumn{2}{|c|}{ Order of Authors Secondary Information: } \\
\hline Abstract: & $\begin{array}{l}\text { The effect of the London urban area on vertical profiles of temperature and humidity } \\
\text { was analyzed using a mesoscale model. It was found that the near-surface warming } \\
\text { and drying effects usually associated with the urban heat island in London in the } \\
\text { summer daytime are reversed at heights near the top of the boundary layer. This effect } \\
\text { has previously been observed for nighttime temperatures above cities and termed a } \\
\text { 'crossover'. The mechanism proposed here to explain this new phenomenon, the } \\
\text { daytime crossover, is similar to the previously suggested cause of the nighttime effect, } \\
\text { that is, increased entrainment of warm dry air into the top of a cooler, more humid, } \\
\text { boundary layer. The median summer daytime temperature crossover was found to be } \\
1.1 \mathrm{~K} \text {. The cooling was shown to be of a similar magnitude to the warming near the } \\
\text { surface and extends up to } 100 \text { km downwind with a maximum magnitude at about } \\
1500 \text { LST in summer. The moistening occurred over a similar spatial scale and peak } \\
\text { values were typically two times greater than the near-surface drying effect. }\end{array}$ \\
\hline Response to Reviewers: & $\begin{array}{l}\text { Dear Editor, } \\
\text { I have revised the manuscript according to the copy-edited manuscript and comments. } \\
\text { Thanks, } \\
\text { Nathan }\end{array}$ \\
\hline
\end{tabular}




\title{
- Numerical simulations of daytime temperature and humidity 2 crossover effects in London
}

\author{
N. Sparks (n. sparks07@imperial.ac.uk) and R. Toumi \\ (r.toumi@imperial.ac.uk)
}

\begin{abstract}
The effect of the London urban area on vertical profiles of temperature and humidity was analyzed using a mesoscale model. It was found that the near-surface warming and drying effects usually associated with the urban heat island in London in the summer daytime are reversed at heights near the top of the boundary layer. This effect has previously been observed for nighttime temperatures above cities and termed a 'crossover'. The mechanism proposed here to explain this new phenomenon, the daytime crossover, is similar to the previously suggested cause of the nighttime effect, that is, increased entrainment of warm dry air into the top of a cooler, more humid, boundary layer. The median summer daytime temperature crossover was found to be $1.1 \mathrm{~K}$. The cooling was shown to be of a similar magnitude to the warming near the surface and extends up to $100 \mathrm{~km}$ downwind with a maximum magnitude at about 1500 UTC in summer. The moistening occurred over a similar spatial scale and peak values were typically two times greater than the near-surface drying effect.
\end{abstract}

Keywords: Crossover, London, Mesoscale model, Numerical modelling, Urban heat island

\section{Introduction}

Studies of the London urban heat island (UHI) date back to at least 1833 when Luke Howard identified the phenomenon, noting that the air temperature in London was often higher than in nearby rural locations (Howard, 1833). More recently several analyses of temperature measurements (Wilby, 2003; Jones and Lister, 2007) report detailed accounts of long-term ruralurban temperature difference in London, while Giridharan and Kolokotroni (2009) and Kolokotroni and Giridharan (2008) provide recently measured diurnal cycles of the London UHI. These studies generally show that, at the surface, the London urban temperature excess (UTE), that is, the increase in temperature due to the urban environment, is nearly always positive, and largest during the night and in summer. Although it is not uncommon for negative values of UTE to occur in the daytime in the centre of large cities this effect is not observed in London (Mavrogianni et al., 2011).

Numerical modelling is now a commonly used tool for investigating the effect of urban areas on the lower atmosphere. The importance of urban effects in mesoscale simulations have been reported in various studies (Sarrat et al., 2006; Zhang et al., 2010, 2011; Chen et al., 2011b; Si et al., 2012).

Recent numerical simulations of the airflow over London have focused on improving the parametrization of the urban land surface in numerical models.

(C) 2014 Kluwer Academic Publishers. Printed in the Netherlands. 
Chemel and Sokhi (2012) show the response of London's heat island to a marine air intrusion and test its sensitivity to the representation of the urban area in the model. Loridan et al. (2013) demonstrate the benefits of an improved urban-land classification scheme on simulations of London's surface energy fluxes.

Most UHI studies focus on air temperature near the surface, within the urban canopy layer, for two reasons: measurements are more easily made at the surface than aloft; the near-surface region is of more interest as this is the layer in which we live. Knowledge of the vertical structure of the $\mathrm{UHI}$ is however important in understanding the controlling processes. Early work by Bornstein (1968) in New York City reveals aspects of the complex structure of the nocturnal heat island. They observed a positive UTE near the surface that reverses in sign at heights between $300 \mathrm{~m}$ and $500 \mathrm{~m}$, an effect they term a 'crossover'. Lee and Olfe (1974) successfully reproduced the observed crossover using a two-dimensional numerical model, and showed that increased urban eddy diffusivity interacting with the nocturnal inversion leads to the crossover. Oke (1982) suggested two possible mechanisms causing the crossover: (a) entrainment at the elevated urban inversion base removing heat from this layer; (b) longwave radiative flux divergence at the top of the urban boundary layer (UBL). In a more recent study Wouters et al. (2013) used a regional climate model to simulate the airflow over Paris in the summertime and found a nocturnal temperature crossover at around 200 to $300 \mathrm{~m}$ in height.

While temperature is usually the focus of UHI studies, the urban surface also affects the humidity in the UBL. Bohnenstengel et al. (2011) show that the London area had a lower near-surface relative humidity during the afternoon and evening although the UTE may affect this result. Both Fortuniak et al. (2006) and Kuttler et al. (2007) contrast rural and urban near-surface absolute humidity (or water vapour pressure) measurements and find that while the urban atmosphere is usually drier, it can also be more humid; that is, there is an urban moisture excess (UME). These UME events were found to be most frequent during summer nights. Many urban humidity studies report a correlation between the UME and UTE (Holmer and Eliasson, 1999; Unkašević et al., 2001; Mayer et al., 2003). Lee (1991) found that in London, near the surface, the UME is positive at night throughout the year and positive during the whole day in the winter and spring, and propose two possible mechanisms to explain the UME. Firstly, higher urban surface temperatures increase evaporation, especially throughout the night, whereas dewfall in rural areas removes moisture from the atmosphere. Secondly, the turbulent nocturnal atmosphere transports more humid air, which has been advected from rural areas, to the surface from higher levels.

In this study the vertical profile of the UTE and UME are examined using a mesoscale modelling approach. It is found that in addition to the documented nocturnal temperature crossover effect, a new phenomenon, the day- 
time crossover, exists for temperature and absolute humidity. The proposed mechanism is a deepening of the boundary layer due to the urban land surface, which cools and moistens the air near the top of the boundary layer through increased mixing. Particular attention is paid to determining the timing, scale and magnitude of these crossovers.

\section{Methodology}

The Advanced Research (ARW) version of the Weather Research and Forecasting model (WRF) version 3.5 (Skamarock et al., 2008) has been adopted using three one-way nested domains with horizontal grid spacings of $25 \mathrm{~km}, 5$ $\mathrm{km}$ and $1 \mathrm{~km}$. Each nest had 50 vertical levels with 11 layers below $2 \mathrm{~km}$. The European Centre for Medium-range Weather Forecasts (ECMWF) Interim Re-Analysis (ERA-Interim) dataset was used to provide initial and boundary conditions, while United States Geological Survey (USGS) data provided the initial land-use categories for the land-surface model. The various parametrization schemes are shown in Table I.

For most of the results presented in this study the Noah land-surface model (LSM) (Chen and Dudhia, 2001) was used to represent the urban land-use category with no explicit urban canopy model (UCM). This is a relatively simple urban model that varies roughness length (although not zero-plane displacement height), surface albedo, emissivity, surface heat capacity, soil thermal conductivity and green vegetation fraction (Liu, 2004). Values of key land-surface parameters used in the Noah LSM for urban and non-urban surfaces are shown in Table II. These modifications have several effects on the land-surface physics: increasing the energy input to the system through the reduced albedo; increasing the thermal inertia through the modified soil thermal properties; reducing evaporation by decreasing the vegetated fraction; changing the surface-layer scaling and turbulence through the increased roughness length.

Modelling on the canopy scale was not deemed necessary as the focus is on the atmosphere well above the canopy layer where values of temperature and humidity should depend predominantly on urban surface fluxes of heat, moisture and momentum on a much larger horizontal scale than the canopy size. However, we do expect sensitivity of the results to the physical parametrization of the urban canopy. To test the sensitivity of our results to the choice of urban LSM the WRF model was also coupled to a single-layer UCM (Chen et al., 2011a) using the default parameters and one urban landuse type. This model takes into account the effect of the geometry of street canyons on shadowing, heat transfer and wind flows and includes multiple surface types (e.g. roofs and roads) as well as anthropogenic heating from human activity. 
Table I. Parametrization schemes used in WRF model.

\begin{tabular}{ll}
\hline Physical process & Parametrization Scheme Used \\
\hline Land surface & Noah land surface model (Chen and Dudhia, 2001) \\
Planetary boundary layer & MYJ (Janjić, 2002) \\
Surface layer & Eta similarity (Janjić, 1994) \\
Longwave radiation & RRTMG (Iacono et al., 2008) \\
Shortwave radiation & RRTMG (Iacono et al., 2008) \\
Microphysics & Lin (Lin et al., 1983) \\
Convection (outer domain only) & Grell-Dévényi (Grell and Dévényi, 2002) \\
\hline
\end{tabular}

Two three-month periods were examined, a winter period from 1 December 2008 to 28 February 2009 and a summer period from 1 June to 31 August 2009. For each period the model was run twice, a control run (CTRL) with the original land-use categories and an experimental run (NOLON) where the land in the London area was modified from 'Urban and built-up' to 'Dryland Cropland and Pasture', which is the prevalent surrounding land-use type. Both urban and non-urban land-surface tiles were initialized with the ERAInterim reanalysis data. The three-month simulations were continuous with no nudging towards the forcing data performed and a spin-up period of 1 day was used. Figure 1 shows the three model nest domains and the modified urban area.

The results presented here are likely to be sensitive to the behaviour of the boundary layer, particularly the turbulent mixing in the boundary layer. In a mesoscale model mixing is principally determined by the planetary boundarylayer (PBL) scheme through the parametrization of turbulence. Three of the most widely used PBL parametrization schemes (MYJ (Janjić, 2002), YSU (Hong et al., 2006), QNSE (Sukoriansky et al., 2005)) were trialled and produced quantitatively similar results. We conclude that the modelled results are robust to changes in the PBL parametrization scheme, and we only show MYJ results here. Of particular interest is the height of the boundary layer, which in the MYJ PBL scheme is calculated as the height at which the turbulent kinetic energy (TKE) decreases to a value of $0.1 \mathrm{~m}^{2} \mathrm{~s}^{-2}$ (Janjić, 2002). 
Table II. Key parameters used in the Noah land-surface model for urban and non-urban land use types in the non-UCM simulation. Non-urban values are for the USGS category 'Dryland Cropland and Pasture' that is prevalent around London. Green vegetation fraction is an approximate value for the area surrounding London and not directly linked to land-use type in the USGS data. The non-urban soil thermal conductivity is variable and dependent on moisture content but is expected to be significantly lower than the fixed urban value.

\begin{tabular}{lllll}
\hline Property & \multicolumn{2}{c}{ Urban } & \multicolumn{2}{c}{ Non-urban } \\
& Summer & Winter & Summer & Winter \\
\hline Albedo (\%) & 15 & 15 & 17 & 23 \\
Roughness length (m) & 0.5 & 0.5 & 0.15 & 0.05 \\
Emissivity (\%) & 88 & 88 & 98.5 & 92 \\
Soil thermal conductivity $\left(\mathrm{W} \mathrm{m}^{-2} \mathrm{~K}^{-1}\right)$ & 3.24 & 3.24 & - & - \\
Surface volumetric heat capacity $\left(\mathrm{MJ} \mathrm{m}^{-3} \mathrm{~K}^{-1}\right)$ & 3.0 & 3.0 & 2.0 & 2.0 \\
Green vegetation fraction (\%) & 5 & 5 & $\sim 35$ & $\sim 50$ \\
\hline
\end{tabular}
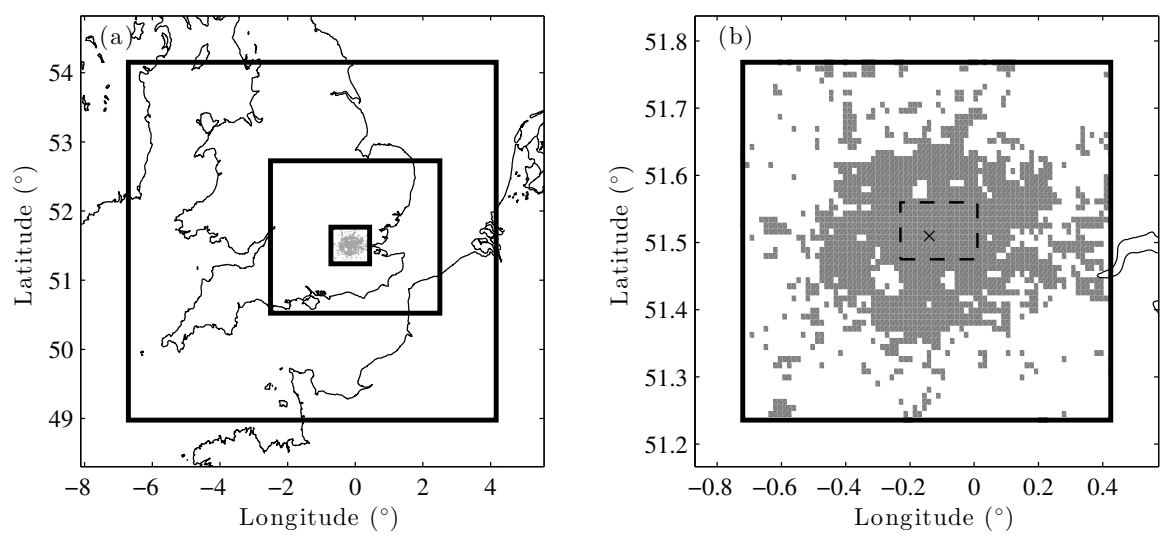

Figure 1. Map of the three model nest domains used shown in (a), the 'Urban' area of London modified to 'Dryland Cropland and Pasture' is shown in grey, (b) the innermost nest is shown, the dashed box outlines the area used to calculate mean central London values. The ' $x$ ' marks the centre of London at $51.5^{\circ} \mathrm{N}-0.13^{\circ} \mathrm{W}$. Land-cover information is from USGS.

\subsection{Surface climatology}

First, the performance of the model in reproducing well-known surface UHI effects is examined. By comparing results of the CTRL and NOLON model runs, the effect of the urbanized area of London can be inferred. The data shown in this section represent average values over the area of central London shown in Fig. 1 for the three-month periods of the summer and winter experiments, and we use results from the non-UCM 1-km simulations. The mean diurnal cycles of UTE ( $\Delta \theta=\theta_{C T R L}-\theta_{N O L O N}$, where $\theta$ is the potential temperature $)$ and $\operatorname{UME}\left(\Delta q=q_{C T R L}-q_{N O L O N}\right.$, where $q$ is the water vapour 
mixing ratio) at a height of $2 \mathrm{~m}$ are shown in Fig. 2. The height of $2 \mathrm{~m}$ was chosen as the standard height for defining an urban heat island (Fortuniak et al., 2006; Sarrat et al., 2006).

In summer there is a strong diurnal cycle of $\Delta \theta$ with a broad daytime minimum of around $1-2 \mathrm{~K}$ and nighttime maximum of $3.5 \mathrm{~K}$. This is very similar to central London observations presented by Kolokotroni and Giridharan (2008) based on measurements at a height of $6 \mathrm{~m}$. As these observations (and others mentioned in this section) are based on point measurements within or at the top of the urban canopy they are representative of a different scale to our grid-box-averaged simulated values. Comparisons between them should therefore be made tentatively and we only state a qualitative similarity here that is sufficient to demonstrate the phenomenon of the daytime crossover.

In the winter the mean magnitude of $\Delta \theta$ is reduced as well as the range of the diurnal cycle. During periods with no incoming shortwave radiation $\Delta \theta$ remains fairly constant at around $0.75 \mathrm{~K}$ and then decreases to just above zero by midday. This is consistent with the measured winter values reported in Wilby (2003). Similarly the UME, $\Delta q$, has a strong cycle in the summer with the city drier than the surroundings for most of the day excluding the period from 0000 to $0600 \mathrm{UTC}$ where there is a positive $\Delta q$. In the winter the range and magnitude of the cycle are reduced but there is an extended small positive $\Delta q$ from 1800 to 0800 UTC. These results are in broad agreement with the measurements of Lee (1991) in London and Fortuniak et al. (2006) in Łódź.

Figure 3 shows diurnal cycles of the change in surface sensible and latent heat flux due to the urban surface, $\Delta Q_{H}$ and $\Delta Q_{E}$ respectively, for summer and winter periods as above. In the summer, $\Delta Q_{H}$ is positive throughout the day with a maximum in the early afternoon where the effects of the reduced urban albedo are strongest, the heat island is however weakest around this point because the excess heat is mixed into a deeper boundary layer. $\Delta Q_{E}$ has very small positive values throughout the night that could contribute to the UME. The negative $\Delta Q_{E}$ during the day, which reaches a minimum around noon, is mainly due to the low vegetation cover of the urban surface and is the main source of the dry island effect during the day. In the winter $\Delta Q_{H}$ has a small positive value throughout the day with no significant diurnal cycle. Winter values of $\Delta Q_{E}$ resemble the summer but display greater variability.

\subsection{Crossover climatology}

Having established the model's qualitative reproduction of the observed nearsurface climatology we now examine the upper boundary layer. A mean daytime crossover is present and is largest at around 1500 UTC and at heights of $1.8 \mathrm{~km}$ and $1.3 \mathrm{~km}$ for temperature and humidity respectively as shown later in this section. Maps of the mean summer 1500 UTC value of $\Delta \theta$ at 2 

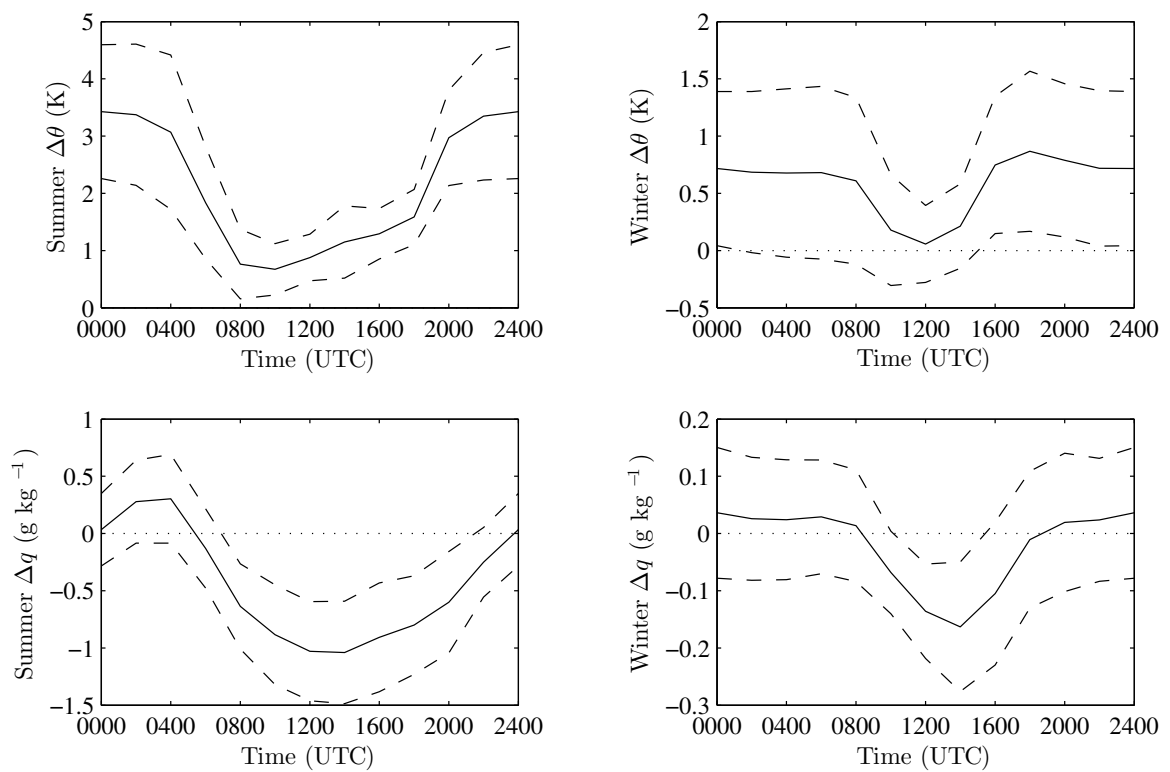

Figure 2. Diurnal $\Delta \theta$ and $\Delta q$ at 2-m height in central London for the summer and winter periods December 2008 to February 2009 and June to August 2009 respectively from the 1-km simulation. Solid line is the mean, dashed lines are plus and minus one standard deviation. Values calculated on means across the boxed area in Fig. 1b comprising 357 grid squares in central London.
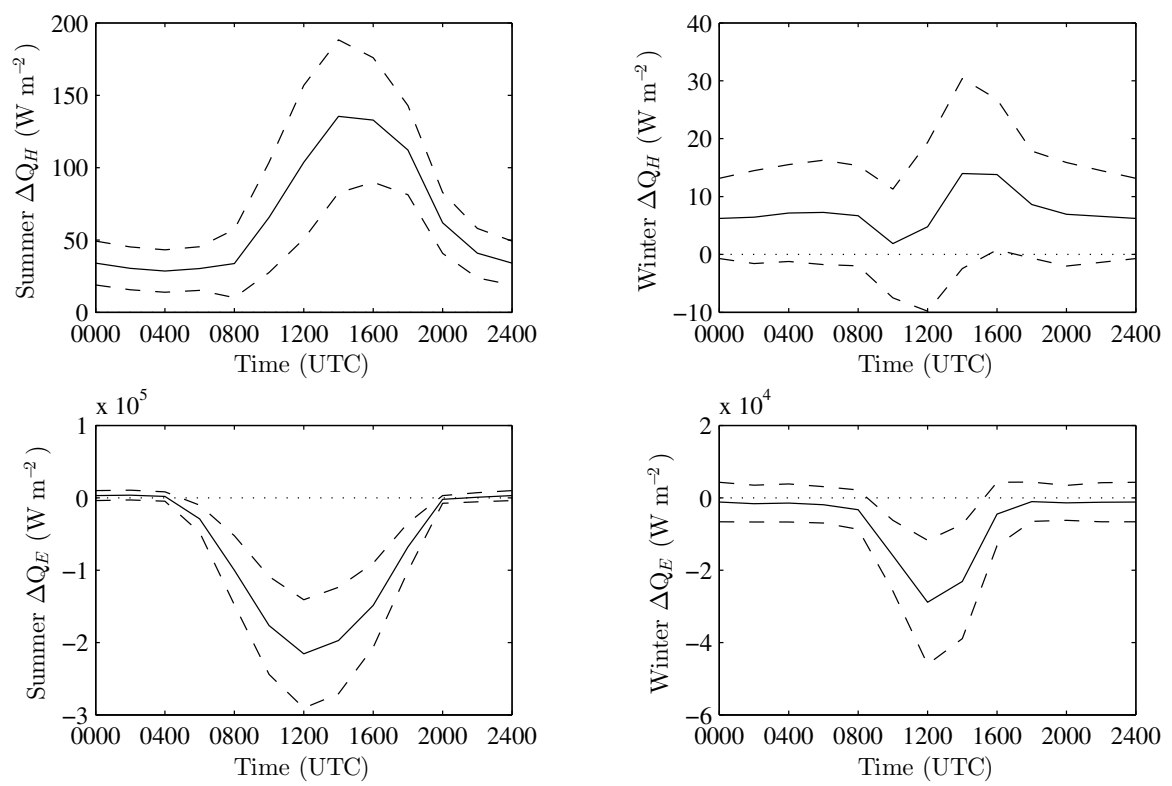

Figure 3. Diurnal cycle of surface sensible heat, $\Delta Q_{H}$, and latent heat, $\Delta Q_{E}$, fluxes calculated as in Fig. 2. 
$\mathrm{m}$ and $1.8 \mathrm{~km}$ and $\Delta q$ at $2 \mathrm{~m}$ and $1.3 \mathrm{~km}$ are shown in Fig. 4 using the 5$\mathrm{km}$ simulation with no urban canopy model. The daytime near-surface heat island and dry island are clearly present in the immediate vicinity of London. In the maps at higher altitudes, the crossover is present with roughly $10 \%$ of the near-surface magnitude for both temperature and humidity. The crossover is centred slightly to the east of the centre of London due to the westerly prevailing wind.

\subsubsection{Sensitivity to model set-up}

Figure 5 repeats the above analysis using data from the UCM simulation. The figures are qualitatively very similar. The main difference is a reduction in the magnitude of the near-surface and crossover effects by approximately $30 \%$ compared to the non-UCM model. The existence of the crossover does not therefore seem sensitive to the particular choice of urban land-surface model but does have a quantitative relation to it. As the simpler non-UCM Noah LSM simulation qualitatively reproduces the observed near-surface urban temperature and humidity behaviour it will be used for the remainder of the analysis.

The above analysis is again repeated in Fig. 6 only this time using the 25$\mathrm{km}$ simulation. At this resolution London is represented by only two adjacent urban tiles. The surface heat island and dry island are both present albeit at slightly reduced magnitudes. The crossovers in temperature and humidity are also present with a similar magnitude to the $5-\mathrm{km}$ simulation. This shows that, while there is some quantitative dependence on horizontal grid spacing, a high horizontal spatial resolution is not necessary to produce a crossover effect and even resolving the urban area as two grid squares appears to be sufficient to produce the effect.

\subsubsection{Crossover magnitude and location}

The magnitude of the temperature crossover at a given time, $\Delta \theta_{\min }$, can be defined as the minimum value of UTE, $\Delta \theta$, in the along-wind vertical crosssection passing through the centre of London in a model domain. Correspondingly, $\Delta \theta_{\max }$ is then the maximum magnitude of the heat island. The humidity crossover leads to a moisture excess, so its magnitude, $\Delta q_{\max }$, is defined as the maximum value of UME, $\Delta q$, in the same cross section described above; $\Delta q_{\min }$ is then the magnitude of the dry-island effect. These values were calculated at 1500 UTC each day in the summer period using the 5-km simulation. Figure 7 shows the magnitude of $\Delta \theta_{\min }$ and $\Delta q_{\max }$ and their respective locations on the cross section. The coldest crossover events typically occur between 0 and $50 \mathrm{~km}$ downwind of the centre of London at a height of just under $2 \mathrm{~km}$. The locations of $\Delta q_{\max }$ are similarly distributed although at a slightly lower height. 

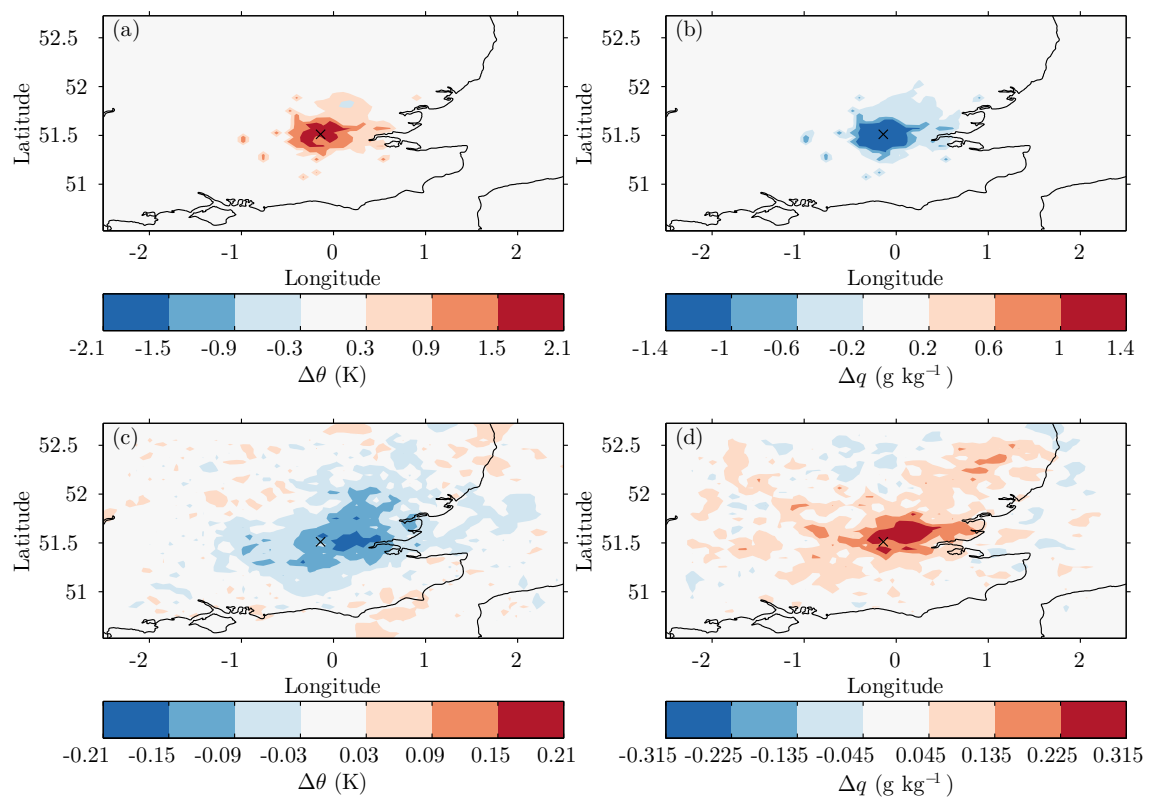

Figure 4. Maps of mean (a) $\Delta \theta$ and (b) $\Delta q$ at 2-m height at 1500 UTC in the summer period June to August 2009 from the 5-km horizontal grid spacing simulation with no urban canopy model. Corresponding values at $1.8 \mathrm{~km}$ and $1.3 \mathrm{~km}$ above ground are shown for $\Delta \theta$ and $\Delta q$ respectively in (c) and (d).
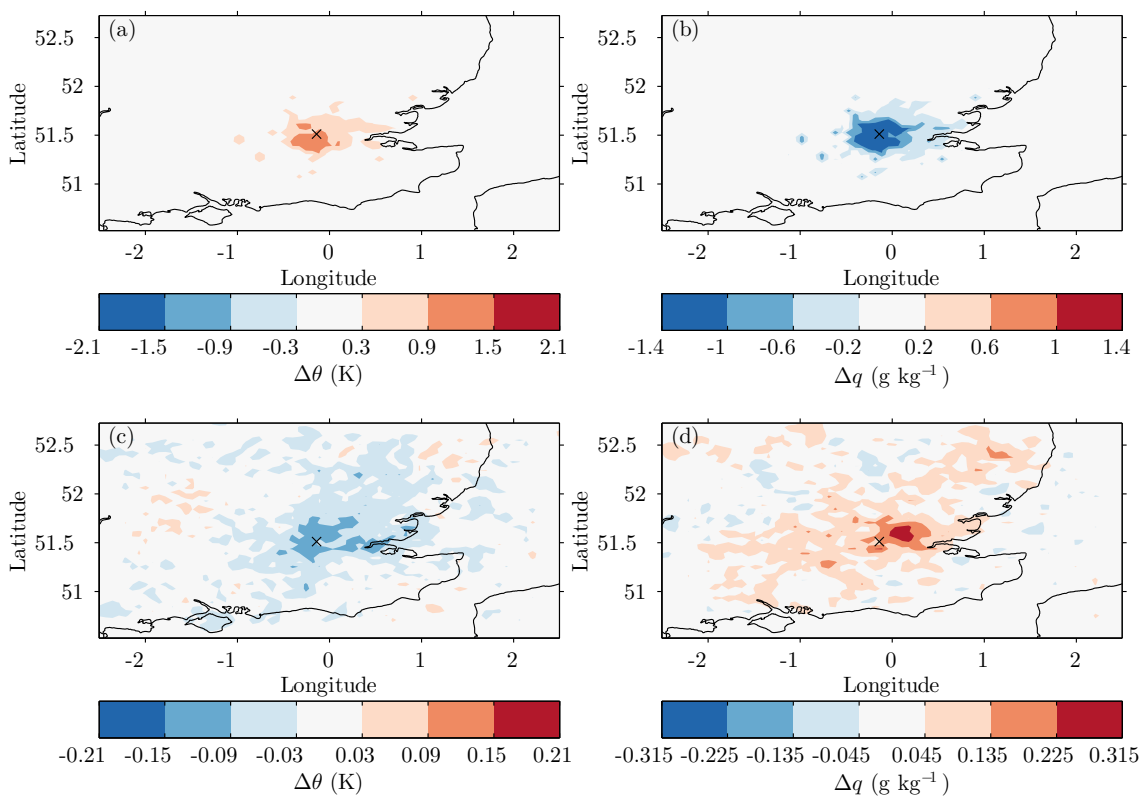

Figure 5. As in Fig. 4 but using the UCM simulation. 

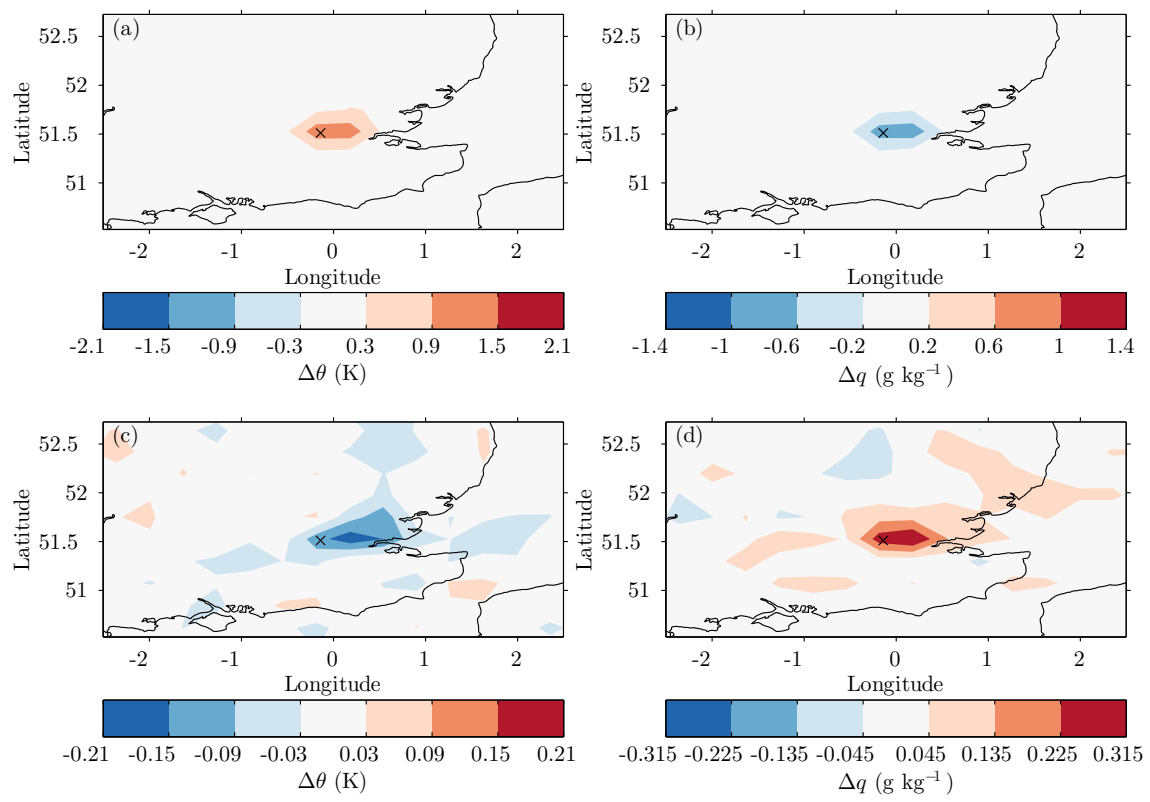

Figure 6. As in Fig. 4 but using the $25-\mathrm{km}$ horizontal grid spacing simulation.

To test the relationship between heat island and crossover magnitude Fig. 8 shows the correlation between $\Delta \theta_{\min }$ and $\Delta \theta_{\max }$; they are anticorrelated with a Pearson's correlation coefficient of $-0.55 . \Delta q_{\max }$ is also correlated with $\Delta \theta_{\max }$ and has a Pearson's correlation coefficient of 0.34 .

Histograms of the four variables, $\Delta \theta_{\min }, \Delta \theta_{\max }, \Delta q_{\max }$ and $\Delta q_{\min }$ are shown in Fig. 9. Values of $\Delta \theta_{\min }$ range from $-0.1 \mathrm{~K}$ to $-2.3 \mathrm{~K}$ with a median of -1.1 $\mathrm{K}$, similar to the median of $\Delta \theta_{\max }$ of $1.3 \mathrm{~K}$. There is therefore a crossover of some form everyday in the summer period and on half of the days the crossover magnitude is $>1.1 \mathrm{~K} . \Delta q_{\max }$ ranges from $0.1 \mathrm{~g} \mathrm{~kg}^{-1}$ to $5.9 \mathrm{~g} \mathrm{~kg}^{-1}$ with a median of $2.0 \mathrm{~g} \mathrm{~kg}^{-1}$, approximately twice the magnitude of the median $\Delta q_{\min }$.

Figures 8 and 9 reveal that the magnitude of the temperature crossover is often similar to that of the near-surface heat island and that the two are correlated; this suggests their mechanisms are linked. An increase in surface sensible heat flux would raise the surface air temperature but would also increase the turbulent mixing and the height to which mixing is significant (i.e. the boundary-layer height). The crossover may then be due to increased mixing at around the boundary-layer height. This theory is explored in more detail in Sect. 3.3. 

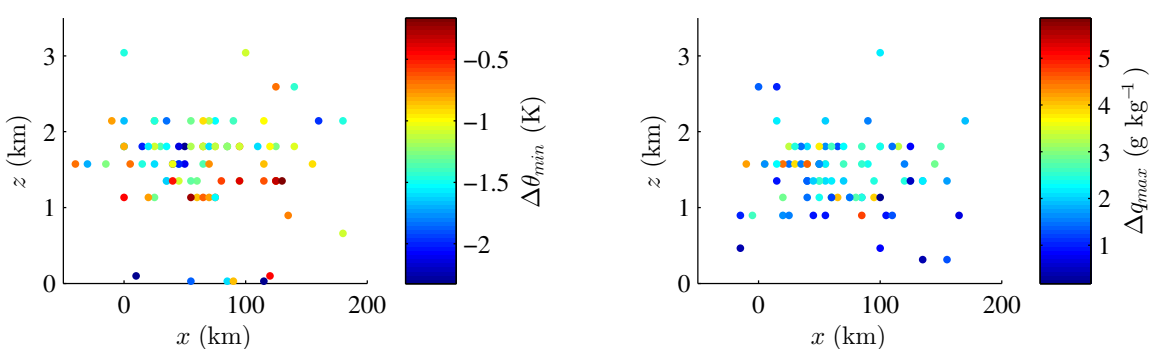

Figure 7. The magnitude and location of peak temperature and humidity crossovers on along-wind cross-sections though the centre of London. Each calculated daily at 1500 UTC in the period 1 June to 31 August 2009. The horizontal axis shows the distance downwind of the centre of London as defined in Fig. 1 and vertical axis is height above ground.
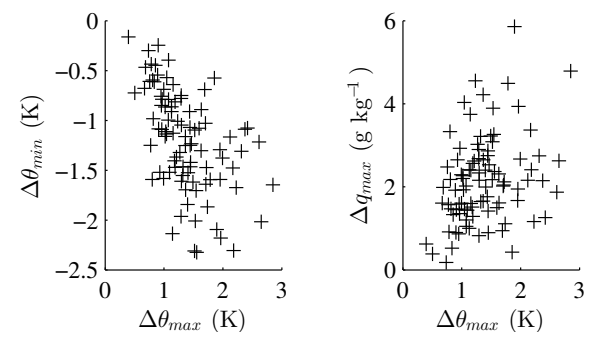

Figure 8. Crossover magnitude for temperature, $\Delta \theta_{\min }$ and humidity, $\Delta q_{\max }$ both plotted against the maximum heat-island magnitude, $\Delta \theta_{\max }$. Each calculated daily at 1500 UTC on along-wind cross-sections through the centre of London in the period 1 June to 31 August 2009.
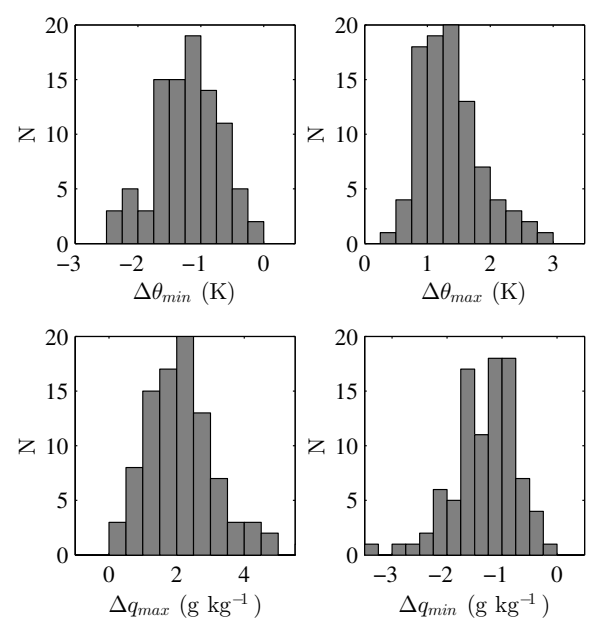

Figure 9. Histograms of $\Delta \theta_{\min }, \Delta \theta_{\max } \Delta q_{\max }$ and $\Delta q_{\min }$. Each calculated daily at 1500 UTC on along-wind cross-sections through the centre of London in the period 1 June to 31 August 2009. 


\subsubsection{Diurnal crossover}

In Fig. 10 the mean diurnal cycle of the central London UTE, $\Delta \theta$, is shown as a function of height above the ground. This was calculated using the 1$\mathrm{km}$ simulation. During the summer, the positive urban heat island extends from the surface up to about $200 \mathrm{~m}$ at night and $1.2 \mathrm{~km}$ at midday, roughly following the variation in boundary-layer height. Above this is the crossover layer. The nocturnal crossover begins developing at around 2200 UTC and lasts until $0700 \mathrm{UTC}$ with a maximum magnitude of $\Delta \theta_{\min } \approx 0.2 \mathrm{~K}$ at a height of 300 to $400 \mathrm{~m}$. The daytime crossover appears to be largely disconnected to the nocturnal crossover and reaches maximum magnitude at a height of 1.8 $\mathrm{km}$ at around 1500 UTC. In winter, the crossover seems to last for the whole day with only a reduction in magnitude during the daytime. The crossover remains at a constant height, roughly 200 to $400 \mathrm{~m}$, throughout the diurnal cycle.

The diurnal cycle of UME, $\Delta q$, is also shown in Fig. 10. In the summer during the day London is a dry island with a vertical extent of up to $1 \mathrm{~km}$ at 1400 UTC. There is also a humidity crossover aloft during the daytime, similar to the temperature crossover described above, with a maximum magnitude of around $0.3 \mathrm{~g} \mathrm{~kg}^{-1}$ at $1500 \mathrm{UTC}$ at a height of approximately $1.5 \mathrm{~km}$. In the winter, above the surface, there is a humidity crossover during most of the day with a peak magnitude at $0.6 \mathrm{~km}$ at 1800 UTC. The effect in the winter is an order of magnitude smaller than in the summer.

The magnitudes of the temperature and humidity crossovers in the mean diurnal cycles appear significantly smaller than the values of $\Delta \theta_{\min }$ and $\Delta q_{\max }$ presented in Fig. 9. This is partly because the peak crossover values usually occur downwind of the centre but also because they occur at varying heights and so are smoothed by the averaging process.

\subsubsection{Crossover spatial extent}

The mean spatial extent of the temperature crossover is also of interest and is examined here. Using data from the $5-\mathrm{km}$ simulation, cross-sections of $\Delta \theta$ through the centre of London and aligned with the direction of the mean wind in central London were calculated for each day at 1500 UTC when the mean crossover effect is near maximum. Figure 11 shows a composite of these cross-sections. Also shown are the boundary-layer heights for the CTRL and NOLON cases. The summer crossover has a mean maximum magnitude $\left(\Delta \theta_{\min }\right.$ ) of around $0.4 \mathrm{~K}$ at $1.8 \mathrm{~km}$ above ground and approximately $30 \mathrm{~km}$ downwind of the centre of London. The regular heat island extends from the surface up to around $1 \mathrm{~km}$ and reaches over $100 \mathrm{~km}$ downwind. In the winter the UHI only reaches about $200 \mathrm{~m}$ above ground and the crossover effect is weaker but present at about $400 \mathrm{~m}$ above ground. The urban boundary-layer height is raised by a maximum of about $400 \mathrm{~m}$ and $200 \mathrm{~m}$ in summer and winter respectively. 

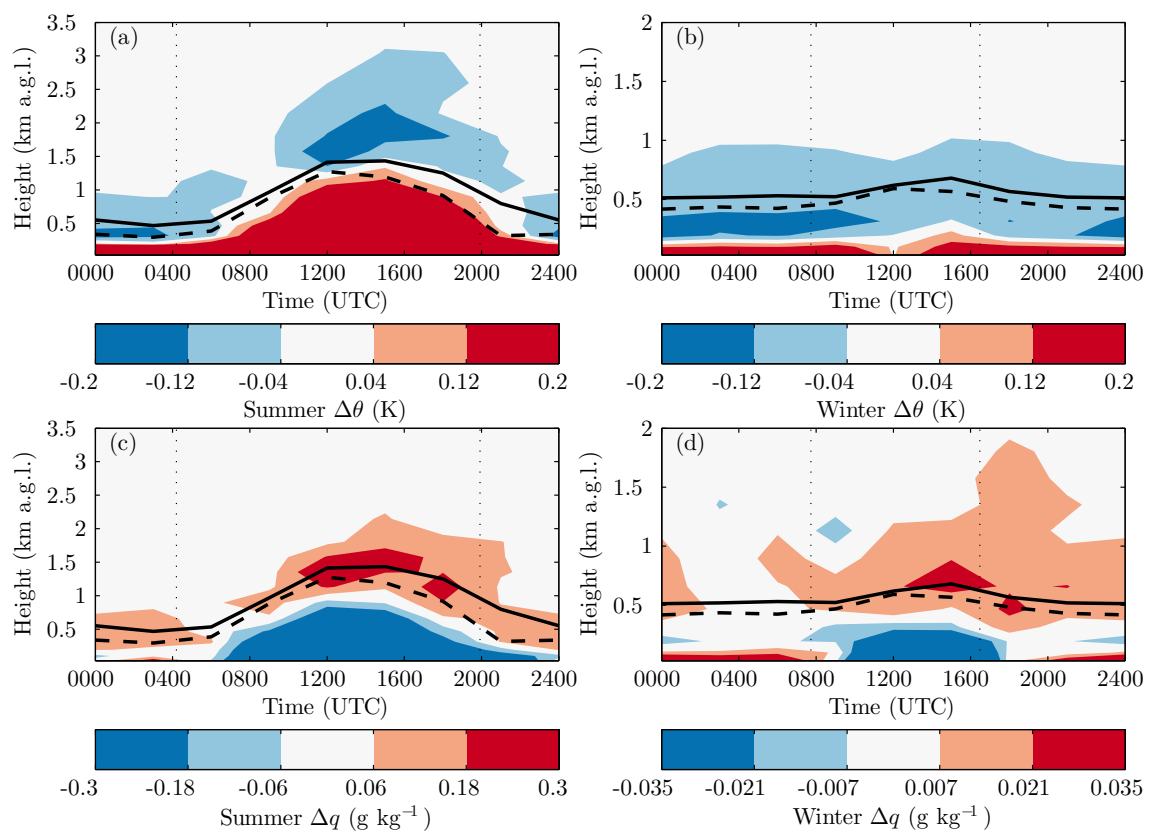

Figure 10. Diurnal $\Delta \theta$ in central London as a function of height above ground are shown in (a) and (b) for the periods June to August 2009 and December 2008 to February 2009 respectively. Corresponding plots for $\Delta q$ are shown in (c) and (d). Solid line shows CTRL boundary-layer height, dashed line shows NOLON boundary-layer height as calculated by the PBL scheme (Janjić, 2002). The vertical dotted lines depict the mean sunrise and sunset times over the three-month period. Note the different vertical scales used for the summer and winter. Data from the 1-km simulation.

Analogous humidity cross-sections are also shown in Fig. 11. In the summer the horizontal distribution is similar to that of the UTE, $\Delta \theta$, although the peak magnitude is lower at around $1.5 \mathrm{~km}$ above ground. The humidity crossover is an order of magnitude smaller and of reduced spatial extent in the winter.

For both temperature and humidity in the summer the crossover magnitude peaks just after the difference between CTRL and NOLON boundary-layer heights reaches a maximum. This is evidence that the boundary-layer height is an important factor in creating the crossover. Further downstream, as the tops of the CTRL and NOLON boundary layer begin to converge, the cooler and moister air in the crossover is advected downstream and still detectable in the mean signal up to $100 \mathrm{~km}$ away. Beyond this the temperature and humidity profiles relax back to the rural values. 

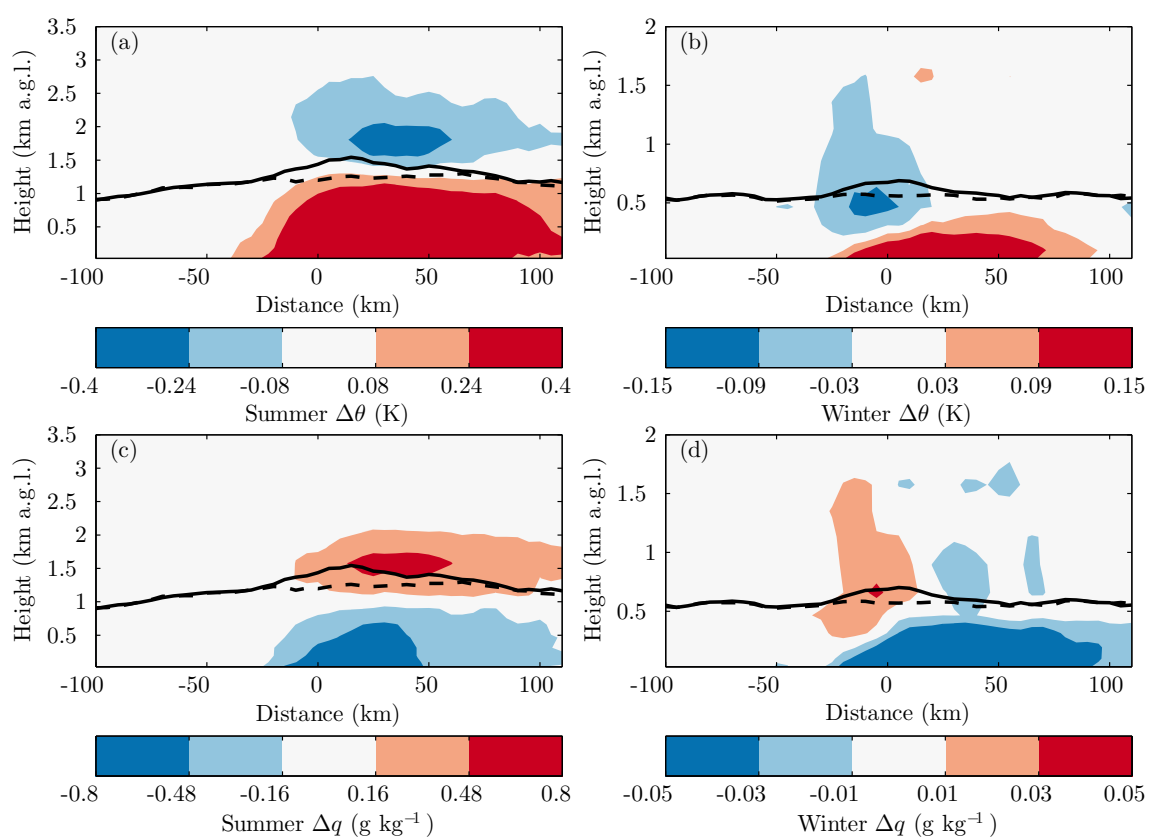

Figure 11. Composite along-wind cross-sections of $\Delta \theta$ at 1500 UTC are shown in (a) and (b) for the periods June to August 2009 and December 2008 to February 2009 respectively. Corresponding plots for $\Delta q$ are shown in (c) and (d). Solid line shows CTRL boundary-layer height, dashed line shows NOLON boundary-layer height. Data from the 5-km simulation. Note the different vertical scales used for the summer and winter.

\subsection{Crossover Event Study}

Having examined the crossover climatology we now present a case study. A daytime crossover event at 1500 UTC on 25 July 2009 is shown in Fig. 12 using data from the 5-km simulation. Maps of UTE, $\Delta \theta$, at $2 \mathrm{~m}$ and $1.8 \mathrm{~km}$ above ground are shown in addition to cross-sections aligned with the wind direction in central London, of $\Delta \theta, \Delta q$ and $\Delta K$, where $K$ is proportional to the turbulent mixing diffusivity and defined as $K=l e^{\frac{1}{2}}, l$ is the master length scale as calculated by Janjić (1990) and $e$ the total kinetic energy in the PBL scheme (Xie et al., 2012). Boundary-layer heights are shown for both the CTRL and NOLON cases. In this event a well-developed heat island and dry island exist from the surface up until just below the NOLON boundary layer height. Between the NOLON and CTRL boundary-layer heights however are strong crossovers where the presence of urbanized London has a cooling and moistening effect. These regions extend from roughly the centre of London to beyond $100 \mathrm{~km}$ downwind of the centre of London.

In Fig. 13, vertical profiles of potential temperature, humidity and diffusivity are shown for the same event $25 \mathrm{~km}$ downwind of the centre of London, 
approximately where the crossover reaches a maximum. The profiles help to explain the origin of the daytime crossovers. In the NOLON case the vertical gradient of potential temperature is close to zero until around $1 \mathrm{~km}$ indicating strong mixing from the ground up until this height, then at $1.2 \mathrm{~km}$ there is an inversion, capping the mixed layer. In the CTRL case, the height of the inversion is increased to around $1.5 \mathrm{~km}$ leading to extra mixing in this height range that is visible in the vertical profile of diffusivity. The vertical profiles of temperature and humidity depend on, amongst other things, the mixing which has occurred upstream, hence the height of the layer of diffusivity excess at this horizontal location does not match up exactly with the height of the crossover layer.

We propose that the following mechanism causes the cooling in the crossover layer: increased sensible heat flux from the urban surface causes the boundary-layer top to rise; as it rises, air in the boundary layer, with a lower potential temperature, is mixed up into air with a higher potential temperature which was previously above the boundary layer. The effect of this mixing is that the air near the top of the deepened boundary layer is cooled while the air below this is warmed. The direction of the effect is reversed in the case of the humidity as the more humid air below is mixed into relatively dry air above. Another way of viewing this is that the air immediately above the rural boundary-layer top is entrained into and mixed throughout the boundary layer as it deepens over the urban surface. This is then similar to the 'entrainment at the elevated inversion base' explanation of the nighttime crossover effect provided by Oke (1982). In this explanation the temperature deficit in the crossover layer occurs because some of its heat has been mixed throughout the boundary layer. Therefore we expect that the mixing process causing the crossover also contributes to the positive heat island below it.

\section{Conclusion}

A mesoscale model was used to reproduce the London urban heat island (UHI) for summer and winter periods using horizontal resolutions of up to $1 \mathrm{~km}$ with a simple parametrization of the urban surface. The model qualitatively reproduces observations of the urban area's effect on near-surface temperature and humidity.

A significant, frequently occurring daytime crossover effect was produced by the simulation. This phenomenon has not previously been reported in either observational or simulation studies. The crossover diurnal cycle and spatial extent have been quantified and in the summer, at least, are similar (but opposite in sign) for temperature and humidity. The median daytime temperature crossover magnitude was $1.1 \mathrm{~K}$ in the summer, similar to the median near-surface UHI magnitude. The median humidity crossover magnitude was 

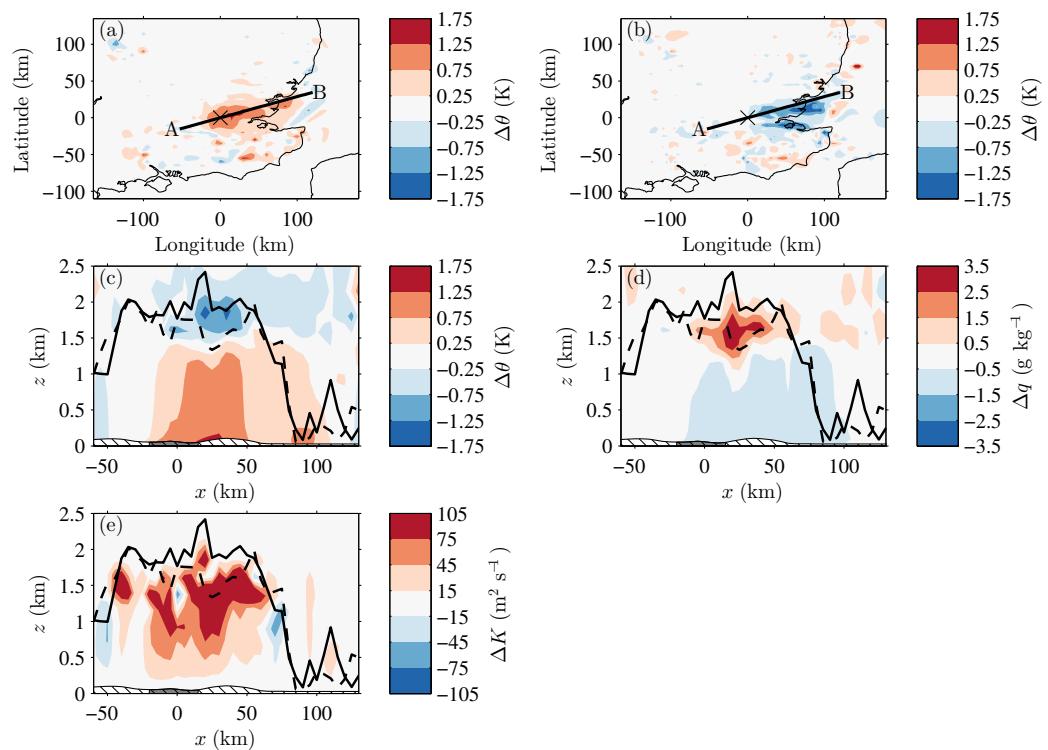

Figure 12. A temperature and humidity crossover event at 1500 UTC on 25 June 2009. $\Delta \theta$ is shown in (a) and (b) at $2 \mathrm{~m}$ and $1.8 \mathrm{~km}$ above ground respectively with the line $\mathrm{AB}$ marking the cross-section shown in other plots. The wind direction is approximately west-south-west. Cross-sections of $\Delta \theta, \Delta q$ and $\Delta K$ are shown in (c), (d) and (e) respectively. Lines in cross sections are boundary-layer heights, dashed line is from the NOLON experiment, solid line is the CTRL run.
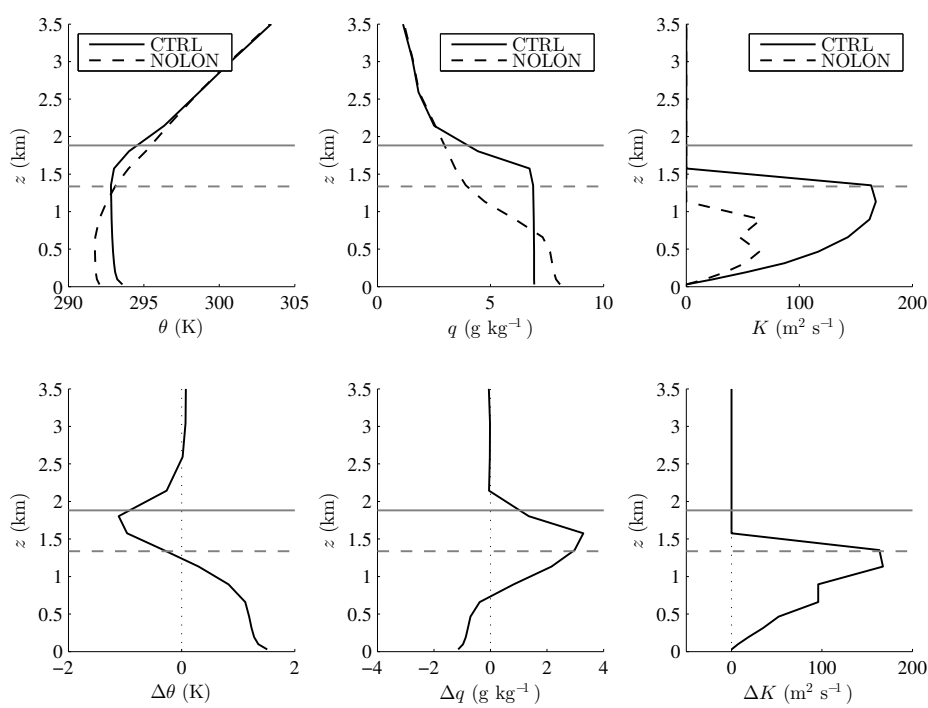

Figure 13. Vertical profiles of $\theta, q, K, \Delta \theta, \Delta q$ and $\Delta K$ at a single grid point $25 \mathrm{~km}$ down wind of central London on the fringes of the city (at the approximate position of maximum crossover) for the event shown in Fig. 12. The surface cover at this grid square is urban. Horizontal lines show boundary-layer heights for CTRL (solid) and NOLON(dashed). 


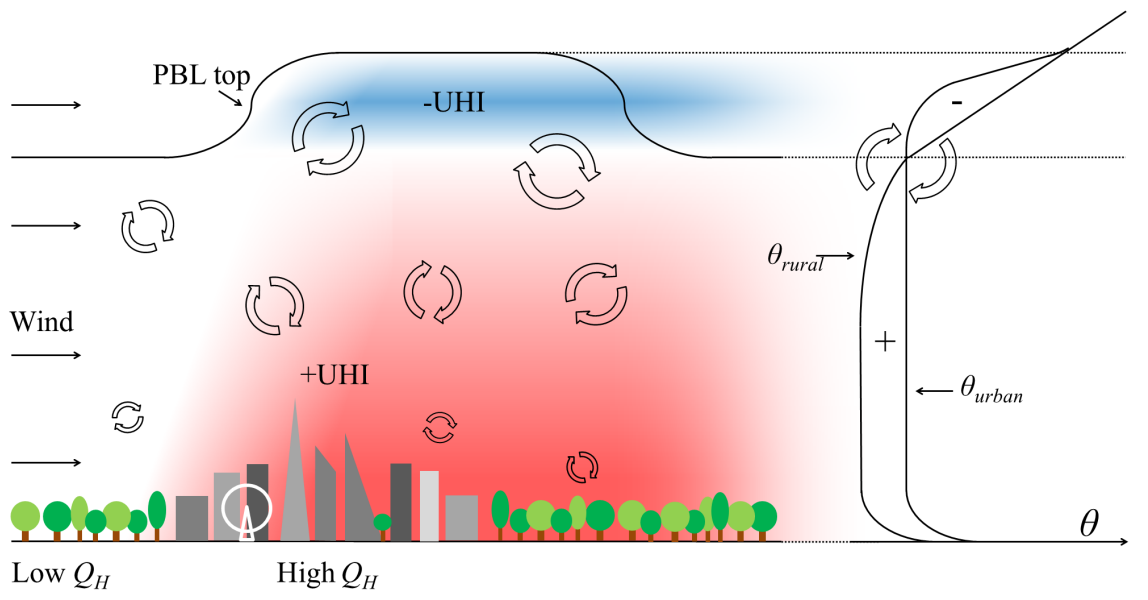

Figure 14. A conceptual figure showing the daytime vertical and horizontal temperature crossover effect. As air is advected over the urban surface, a sensible heat flux, $Q_{H}$, induces warming of the lower boundary layer, increasing the boundary-layer height as turbulent mixing increases. Where the boundary layer has deepened a temperature crossover (negative UHI) exists. The boundary-layer height returns to rural values downwind of the city but the cool air from the crossover is advected beyond this. Typical urban and rural potential temperature profiles are shown on the same axes. The arrows depict mixing of the lower, cooler rural air up into the deeper urban boundary layer and the warmer, higher rural air down into the lower urban boundary layer.

twice the size of the surface effect. Peak crossover values tend to occur 30 $\mathrm{km}$ downwind of the centre of London near the top of the boundary layer. We propose that increased mixing near the top of the urban boundary layer interacting with the inversion in the vertical temperature profile is the principal mechanism causing the crossover. A conceptual diagram of the temperature crossover effect is shown in Fig. 14.

We believe this to be the first study of daytime urban crossover effects. One reason for this, no doubt, is that it is very difficult to observe this effect, given that it is necessary to detect a relatively small temperature (or humidity) difference compared to a variable rural background, $30 \mathrm{~km}$ downwind of a city centre at approximately $2 \mathrm{~km}$ above the ground. It is more surprising that this effect has not been documented in modelling studies, perhaps because the focus there is usually on or near the surface where the impacts of urbanization on the local climate are greatest. urban heat island'. Q. J. R. Meteorol. Soc. 137(659), 1625-1640. 
Bornstein, R.: 1968, 'Observations of the urban heat island effect in New York City'. J. Appl. Meteorol. 7, 575-582.

Chemel, C. and R. S. Sokhi: 2012, 'Response of Londons Urban Heat Island to a Marine Air Intrusion in an Easterly Wind Regime'. Boundary-Layer Meteorol. 144(1), 65-81.

Chen, F. and J. Dudhia: 2001, 'Coupling an Advanced Land Surface - Hydrology Model with the Penn State - NCAR MM5 Modeling System. Part I: Model Implementation and Sensitivity'. Mon. Weather Rev. 129(4), 569-585.

Chen, F., H. Kusaka, R. Bornstein, J. Ching, C. S. B. Grimmond, S. Grossman-Clarke, T. Loridan, K. W. Manning, A. Martilli, S. Miao, D. Sailor, F. P. Salamanca, H. Taha, M. Tewari, X. Wang, A. a. Wyszogrodzki, and C. Zhang: 2011a, 'The integrated WRF/urban modelling system: development, evaluation, and applications to urban environmental problems'. Int. J. Climatol. 31(2), 273-288.

Chen, F., S. Miao, M. Tewari, J.-W. Bao, and H. Kusaka: 2011b, 'A numerical study of interactions between surface forcing and sea breeze circulations and their effects on stagnation in the greater Houston area'. J. Geophys. Res. 116(D12), D12105.

Fortuniak, K., K. Kłysik, and J. Wibig: 2006, 'Urban-rural contrasts of meteorological parameters in Łódź'. Theor. Appl. Climatol. 84(1-3), 91-101.

Giridharan, R. and M. Kolokotroni: 2009, 'Urban heat island characteristics in London during winter'. Sol. Energy 83(9), 1668-1682.

Grell, G. A. and D. Dévényi: 2002, 'A generalized approach to parameterizing convection combining ensemble and data assimilation techniques'. Geophys. Res. Lett. 29(14), 38$1-38-4$.

Holmer, B. and I. Eliasson: 1999, 'Urbanrural vapour pressure differences and their role in the development of urban heat islands'. Int. J. Climatol. 1009, 989-1009.

Hong, S., Y. Noh, and J. Dudhia: 2006, 'A new vertical diffusion package with an explicit treatment of entrainment processes'. Mon. Weather Rev. 134, 2318-2341.

Howard, L.: 1833, The climate of London, Vol. 1. London: Harvey and Darton, 3rd edition.

Iacono, M. J., J. S. Delamere, E. J. Mlawer, M. W. Shephard, S. a. Clough, and W. D. Collins: 2008, 'Radiative forcing by long-lived greenhouse gases: Calculations with the AER radiative transfer models'. J. Geophys. Res. 113(D13), D13103.

Janjić, Z.: 1990, 'The step-mountain coordinate - physical package'. Mon. Weather Rev. 118(7), 1429-1443.

Janjić, Z.: 1994, 'The step-mountain eta coordinate model: Further developments of the convection, viscous sublayer, and turbulence closure schemes'. Mon. Weather Rev. 122, 927-945.

Janjić, Z.: 2002, 'Nonsingular implementation of the MellorYamada level 2.5 scheme in the NCEP Meso model'. National Centers for Environmental Prediction Office note pp. 1-61.

Jones, P. D. and D. H. Lister: 2007, 'The urban heat island in Central London and urban-related warming trends in Central London since 1900'. Weather pp. 323-327.

Kolokotroni, M. and R. Giridharan: 2008, 'Urban heat island intensity in London: An investigation of the impact of physical characteristics on changes in outdoor air temperature during summer'. Sol. Energy 82(11), 986-998.

Kuttler, W., S. Weber, J. Schonnefeld, and A. Hesselschwerdt: 2007, 'Urban / rural atmospheric water vapour pressure differences and urban moisture excess in Krefeld, Germany'. Int. J. Climatol. 2015, 2005-2015.

Lee, D. O.: 1991, 'Urban rural humidity differences in London'. Int. J. Climatol. 11(5), 577582.

Lee, R. and D. Olfe: 1974, 'Numerical calculations of temperature profiles over an urban heat island'. Boundary-Layer Meteorol. 7, 39-52.

Lin, Y., R. Farley, and H. Orville: 1983, 'Bulk parameterization of the snow field in a cloud model'. J. Clim. Appl. Meteorol. 22, 1065-1092. 
Liu, Y.: 2004, 'Improvements to surface flux computations in a non-local-mixing PBL scheme, and refinements to urban processes in the NOAH land-surface model with the NCAR/ATEC real-time FDDA and forecast system'. In: 20th Conference on Weather Analysis and Forecasting/16th Conference on Numerical Weather Prediction.

Loridan, T., F. Lindberg, O. Jorba, S. Kotthaus, S. Grossman-Clarke, and C. S. B. Grimmond: 2013, 'High Resolution Simulation of the Variability of Surface Energy Balance Fluxes Across Central London with Urban Zones for Energy Partitioning'. Boundary-Layer Meteorol. 147(3), 493-523.

Mavrogianni, a., M. Davies, M. Batty, S. Belcher, S. Bohnenstengel, D. Carruthers, Z. Chalabi, B. Croxford, C. Demanuele, S. Evans, R. Giridharan, J. Hacker, I. Hamilton, C. Hogg, J. Hunt, M. Kolokotroni, C. Martin, J. Milner, I. Rajapaksha, I. Ridley, J. Steadman, J. Stocker, P. Wilkinson, and Z. Ye: 2011, 'The comfort, energy and health implications of London's urban heat island'. Build. Serv. Eng. Res. Technol. 32(1), 35-52.

Mayer, H., a. Matzarakis, and M. G. Iziomon: 2003, 'Spatio-temporal variability of moisture conditions within the Urban Canopy Layer'. Theor. Appl. Climatol. 76(3-4), 165-179.

Oke, T.: 1982, 'The energetic basis of the urban heat island'. Q. J. R. Meteorol. Soc. 108(455), $1-24$.

Sarrat, C., a. Lemonsu, V. Masson, and D. Guedalia: 2006, 'Impact of urban heat island on regional atmospheric pollution'. Atmos. Environ. 40(10), 1743-1758.

Si, P., Y. Ren, D. Liang, and B. Lin: 2012, 'The combined influence of background climate and urbanization on the regional warming in Southeast China'. J. Geogr. Sci. 22(2), 245-260.

Skamarock, W., J. Klemp, and J. Dudhia: 2008, 'A description of the advanced research WRF version 3'. NCAR Tech. Note.

Sukoriansky, S., B. Galperin, and V. Perov: 2005, 'Application of a new spectral theory of stably stratified turbulence to the atmospheric boundary layer over sea ice'. Boundarylayer Meteorol. 117(2), 231-257.

Unkašević, M., O. Jovanović, and T. Popović: 2001, 'Urban-suburban/rural vapour pressure and relative humidity differences at fixed hours over the area of Belgrade city'. Theor. Appl.... 73, 67-73.

Wilby, R.: 2003, 'Past and projected trends in London's urban heat island'. Weather 58, 251-260.

Wouters, H., K. De Ridder, M. Demuzere, D. Lauwaet, and N. P. M. van Lipzig: 2013, 'The diurnal evolution of the urban heat island of Paris: a model-based case study during Summer 2006'. Atmos. Chem. Phys. 13(17), 8525-8541.

Xie, B., J. C. H. Fung, A. Chan, and A. Lau: 2012, 'Evaluation of nonlocal and local planetary boundary layer schemes in the WRF model'. J. Geophys. Res. 117(D12), D12103.

Zhang, D.-L., Y.-X. Shou, R. R. Dickerson, and F. Chen: 2011, 'Impact of Upstream Urbanization on the Urban Heat Island Effects along the WashingtonBaltimore Corridor'. $J$. Appl. Meteorol. Climatol. 50(10), 2012-2029.

Zhang, N., Z. Gao, X. Wang, and Y. Chen: 2010, 'Modeling the impact of urbanization on the local and regional climate in Yangtze River Delta, China'. Theor. Appl. Climatol. 102(3-4), $331-342$. 